\title{
$\mathrm{DCT}$ 기반 워터마킹의 적응적 강인화 방법 \\ 전 영 민 ${ }^{\dagger}$ 김 계 영 ${ }^{\dagger+}$ 최 형 일 ${ }^{\dagger+}$
}

요 약

본 논문에서는 인간시각에 대한 워터마크의 무감지성을 향상하고 워터마크를 제거하고자 하는 공격에 강인한 워터마킹 방법을 제안한다. 제 안하는 방법은 워터마크를 삽입할 대상의 DCT 블록에 대한 인간의 시각적인 특성을 고려하여 워터마크의 삽입 여부와 블록에 삽입될 워터마 크의 위치와 강도를 적응적으로 결정한다. 워터마크될 블록을 선택하기 위하여 사용되는 특징은 텍스쳐, 휘도, 대비이다. 본 논문은 제안된 방 법의 성능을 평가하기 위하여 절단, 영상강화, 저주파 필터링, JPEG 압축의 영상처리 공격에 대한 실험결과를 보인다.

\section{A adaptively robust method of DCT-based watermarking}

\author{
Young-Min Jun $^{\dagger} \cdot$ Gye-Young $\mathrm{Kim}^{\dagger \dagger} \cdot$ Hyung-Il Choi ${ }^{\dagger \dagger}$
}

\begin{abstract}
In this paper, we propose an improved method of watermarking to increase the invisibility of a watermark and robustness against attacks for the purpose of removing the embedded watermark. The proposed method adaptively selects DCT blocks and determines position and intensity for watermarking based on the characteristics of human visual system. The used features are texture, luminance and contrast. We show the experimental results against image processing attacks such as cropping, image enhancement, low pass filtering, and JPEG compression, and then discuss the performance of the proposed method.
\end{abstract}

키워드 : 디지털 워터마킹(Digital Watermarking), 텍스쳐 분석(Texture Analysis), 휘도 분석(Luminance Analysis), 대비 분석(Contrast Analysis), 적응성(Adaptiveness), 강인성(Robustness)

\section{1. 서 론}

디지털 워터마킹은 저작권 정보인 워터마크를 멀티미디어 컨텐츠에 직접 삽입함으로 멀티미디어 컨텐츠에 대한 저작 권보호와 비인가된 접근 또는 조작을 방지할 수 있는 기술 이다[1-3]. 즉, 저작권 정보가 삽입된 멀티미디어 컨텐츠가 복제되면 삽입한 저작권 정보도 같이 복제되므로 추출된 워터마크와 제시된 워터마크의 비교를 통하여 그 권리의 진위를 판단할 수 있다. 따라서, 디지털 워터마킹은 불법복 제 방지를 통하여 저작권 보호와 멀티미디어 컨텐츠 산업 의 육성을 위해서 중요한 연구 분야이다.

디지털 워터마킹은 공간 영역에 워터마크를 삽입하는 방 법과 주파수 영역에 워터마크를 삽입하는 방법으로 나눌 수 있다[2]. 전자의 방법은 입력영상 자체에 워터마크를 삽입 하는 것으로 잡음이나 영상처리에 의하여 워터마크가 손실

† 준 회 원 : 숭실대학교 대학원 컴퓨터학부

†† 종신회원 : 숭실대학교 컴퓨터학부 교수

††† 종신회원 : 숭실대학교 미디어학부 교수

논문접수 : 2003년 5월 23일, 심사완료 : 2003년 8월 2I일
될 위험이 큰 단점이 있다. 후자의 방법은 입력영상을 $D C T$ (Discrete Cosine Transform), FFT (Fast Fourier Transform), DWT(Discrete Wavelet Transform) 등의 변환 기 술을 사용하여 주파수 영역으로 바꾼 후 이 영역에 워터마 크를 삽입하는 것이다. 물론, 삽입되는 워터마크도 주파수 영역으로 변환되어야 한다. 입력영상을 주파수 영역으로 변 환하는 기술 중에서 $D C T$ 는 $J P E G$ 과 $M P E G$ 등의 영상압 축 국제표준에서 채택된 방법이므로 워터마킹 분야에서 많 이 활용된다 $[3,4]$.

$D C T$ 기반 워터마킹 방법은 [2]에서 처음 제안되었다. 이 방법에서는 입력영상을 $8 \times 8$ 볼록들로 분할하여 각 블록에 $D C T$ 를 수행한 후, 중간 주파수 영역의 계수를 두 개씩 쌍 으로 선택하여 두 계수간의 차가 양수 또는 음수가 되도록 기존 계수 값을 변경하므로써 워터마크 정보를 삽입한다. 양수 또는 음수의 결정은 이진수 워터마크 값을 기준으로 한다. [3]에서도 비슷한 방법을 제안했는데, 그 차이점은 분 할된 $D C T$ 블록들 중에서 두 개씩 쌍으로 선택하여 동일한 위치의 중간 주파수의 계수 값을 수정하는 것이다. [4]에서 
는 에너지 차를 이용한 워터마킹 방법을 제안했다. 이 방법 은 우선 $D C T$ 블록들을 같은 크기의 두 부분집합으로 분할 하고, 분할된 두 부분집합 중 하나의 부분집합을 구성하는 블록 상의 고주파 계수 값들에 대하여 삽입되는 워터마크 정보에 따라 선택적으로 제거하는 방법으로 에너지 차이를 발생시켜서 워터마크를 삽입하게 된다. [4]의 방법은 [2,3] 의 방법과 비교할 때 워터마크의 강건성과 시각적 무감지 성은 높지만 1 비트의 워터마크를 삽입하기 위하여 누 개의 $D C T$ 블록을 사용한다는 점에서 정지영상보다는 동영상에 적합한 방법이다.

워터마킹 방법이 발전하면서 [2-4]와는 달리, 인간의 시 각적인 특성을 활용하는 적응적 워터마킹 방법이 제안되었 다. 그 대표적인 예는 [5]에서 제안된 지각적 $D C T$ 기반 워 터마킹 방법이다. 이 방법의 특징은 인간시각의 마스킹 효 과를 이용하여 워터마크를 삽입하므로 워터마크의 시각적 인 무감지성과 강인성을 향상시키고 있다. 그러나, [5]의 방 법은 인간시각의 마스킹 효과를 이용한 워터마크를 삽입할 때, 단순히 영상대비 만을 사용하였기 때문에 영상에서 포 함하는 물체와 배경의 경계부근에 삽입한 워터마크가 노출 되는 단점이 있다.

본 논문에서는 기존 방법의 단점을 보완하여 인간시각에 대한 워터마크의 무감지성을 향상시킬 뿐만 아니라 워터마 크를 제거하고자 하는 영상처리 공격에도 강인한 워터마킹 방법을 제안한다. 제안하는 방법은 인간시각의 기초적인 특 성을 모방한 계산적 모델을 활용하여 워터마크를 삽입하는 블록을 결정하고, 결정된 블록상의 워터마크를 삽입할 위치 와 삽입할 강도를 해당 블록의 특징에 따라 적응적으로 결 정하므로 워터마크의 무감지성과 강인성을 강화한다.

본 논문은 다음과 같이 구성된다. 2절에서는 제안한 워터 마킹 방법의 개요를, 3 절에서는 텍스쳐 분석을 통하여 워터 마크를 삽입할 블록을 선택하는 방법을, 4절에서는 휘도와 대비 분석을 통하여 삽입하는 워터마크의 강도산출하는 방 법을, 5절에서는 워터마크를 삽입하고 삽입 이전과 이후의 시각적 무감지성을 검사하여 그 결과에 따라 워터마크의 강도를 조절하는 적응적 워터마킹 방법을 설명한다. 6절에 서는 본 논문에서 제안한 방법에 대한 실험 결과를 보이고, 마지막으로 7절에서 결론을 맺는다.

\section{2. 제안한 워터마킹 방법의 개요}

제안하는 워터마킹 방법은 JPEG 영상압축에 관하여 연 구한 Watson의 논문[9]에 기초를 두고 있으며 전체적인 과 정은 다섯 단계로 이루어진다. 첫 번째 단계는 영상품질 변 화에 대한 인간시각의 기본 민감도를 검사하고, 두 번째 단 계는 시각 마스킹 효과를 계산하며, 세 번째 단계는 인간시
각의 기본 민감도와 시각 마스킹 효과의 계산 결과에 근거 하여 워터마크를 삽입한다. 그리고 네 번째 단계는 워터마 크 삽입전후의 시각적 무감지성을 검사하고, 마지막으로 다 섯 번째 단계는 시각적 무감지성을 만족하는 조건에서 워 터마크의 강도를 조절한다[9].

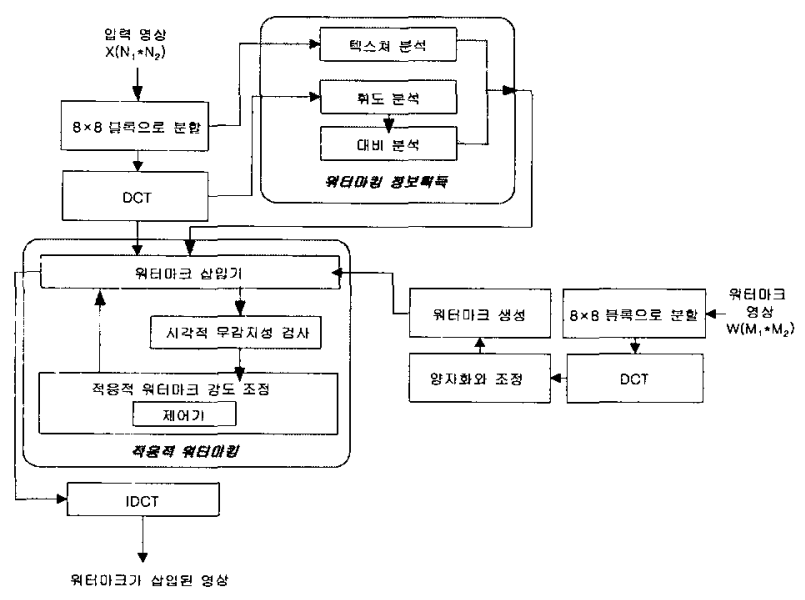

(그림 1) 제안한 워터마킹 방법의 개요도

(그림 1)은 위의 과정을 도식적으로 보여주고 있다. 워터 마킹 정보획득 단계에서의 정보 수집 방법은 각 블록에 대 한 텍스쳐, 휘도, 대비 분석이다. 텍스쳐 분석을 통해 워터 마크의 삽입 위치가 획득되고, 휘도와 대비 분석을 통해 삽 입되는 워터마크 강도가 획득된다. 적응적 워터마킹 단계는 워터마크 삽입기, 워터마크의 시각적 무감지성 검사기, 제 어기로 구성되며, 워터마크 삽입기에서는 $D C T$ 된 영상 블 록과 워터마크 그리고, 워터마킹 정보획득 단계에서 수집된 워터마크의 삽입위치 및 삽입강도를 입력받아 워터마크를 삽입하고, 시각적 무감지성 검사기에서는 삽입한 워터마크 의 시각적인 무감지성을 검사하고, 제어기에서 시각적인 무 감지성 검사결과에 따라서 워터마크의 시각적 무감지성을 만족하는 조건에서 워터마크를 제거하기 위한 공격에 대한 강인성 조건을 극대화하도록 적응적으로 삽입된 워터마크 의 강도를 조정한다.

\section{3. 텍스쳐 분석에 의한 워터마킹 블록 선택}

텍스쳐 분석은 워터마크를 삽입하여도 인간시각의 시각 마스킹 효과로 인하여 쉽게 인식할 수 없는 워터마크의 삽 입 위치를 찾기 위한 과정이다. 텍스쳐 분석은 다음과 같이 세 단계로 구성된다. 첫째, 식 (1)과 같이 입력영상 $X$ 를 $N$ 개의 $8 \times 8$ 블록으로 분할하고, 식 (2)를 통해 블록상의 에지 를 구한다. 이 때 에지검출기는 잡음에 덜 민감한 가우시안 -라플라시안(Laplacian of Gaussian)을 사용한다[8]. 둘째, 검출된 에지들 중에서 물체의 경계에 해당하는 명확한 에 
지들은 제외한다. 그 이유는 영상에서 물체의 경계에 해당 하는 에지와 그 인접 영역에 워터마크를 삽입하면 "울림효 과(ring effects)"를 발생시켜 삽입한 워터마크가 노출되기 때문에 워터마크 삽입후보영역에서 제외하기 위함이다. 제 외 방법은 영상 임계 값을 에지 검출기와 함께 사용하여 물체의 경계에 해당하는 강한 에지를 강조하고 텍스쳐에 해당하는 약한 에지는 약화시켜 물체의 경계에 해당하는 명확한 에지를 검출한 후, 첫 단계에서 구한 에지중 둘째 단계에서 구한 에지들을 제외하는 것이다.

$$
\begin{aligned}
& \text { Images } X=\bigcup_{k=0}^{N-1} B_{k}=\bigcup_{k=0}^{N-1} f_{k}(x, y) \quad x, y=0 \cdots 7 \\
& \operatorname{Edge~}_{k}(x, y)=\left\{\begin{array}{ll}
1 & \text { if Temp } \\
0 & \text { otherwise }
\end{array}, y\right)=\text { 영 교차 } \\
& \operatorname{Temp}_{k}(x, y)=f_{k} \times \text { LoG } \\
& \operatorname{LoG}(x, y)=\frac{1}{\pi \sigma^{4}}\left[1-\frac{x^{2}+y^{2}}{2 \sigma^{2}}\right] e \frac{-\left(x^{2}+y^{2}\right)}{2 \sigma^{2}}
\end{aligned}
$$

셋째는 텍스쳐 분석의 마지막 단계로 영상을 구성하는 모 든 블록들에 대해 텍스쳐 복잡도를 계산하여 복잡도 임계 값 에 따라 세 부류 즉, 단순한 블록 $C_{1}$, 보통인 블록 $C_{2}$, 복잡 한 블록 $C_{3}$ 로 분류한다. 제안하는 방법의 덱스쳐 복잡도는 두 번째 단계에서 얻어진 결과 영상의 각 블록에 포함하는 에지화소의 수를 사용하여 계산한다.

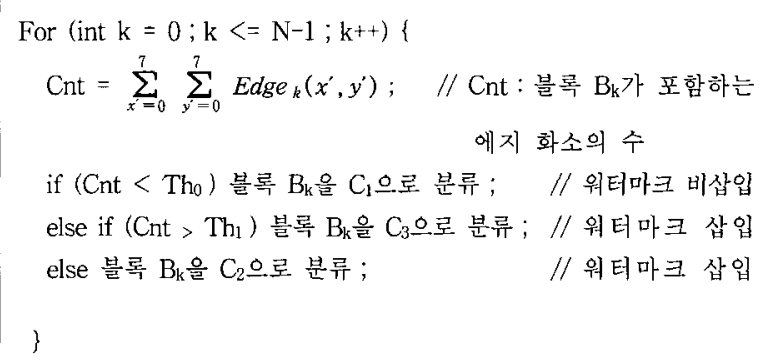

(알고리즘 1) 텍스쳐 복잡도 계산에 의한 워터마킹 블록분류

해당 블록이 (알고리즘 1)에 의해 어떤 부류로 분류 되느 냐에 따라 해당 블록 상에 워터마크의 삽입 여부와 위치가 결정되며 각 부류에 대한 워터마크 삽입 위치는 (그림 2)와 같다. 실험에서 사용되는 복잡도에 관한 임계값 $T h_{0}, T h_{1}$ 은 14,28 을 사용한다.

\section{4. 휘도와 대비 분석에 근거한 워터마크 강도 산출}

휘도와 대비 분석의 목적은 워터마크를 삽입할 때, 삽입 하는 워터마크 강도를 모든 워터마크 삽입 위치에 동일하 게 적용하는 것이 아니라 해당 블록의 휘도와 대비 특징에 따라 차등적으로 적용하여 워터마크의 시각적 무감지성을
확보하고, 시각적 무감지성 제약을 허용하는 조건에서 워터 마크 삽입 강도를 최대로 하여 워터마크 제거 공격에 대한 저항과 워터마크 검출율을 높이는 것이다.

휘도 분석은 휘도 마스킹을 계산하는 과정이다. 휘도 마 스킹이란 영상 영역의 휘도 값이 클수록 어떤 신호가 추가 되어도 추가된 신호로 인한 영상의 품질변화를 인식하기 어려운 인간시각의 특성이다[9]. 본 절에서는 휘도 마스킹 을 영상의 평균 밝기 값 보다 해당 $D C T$ 블록의 평균 밝기 값이 더 밝을수록 워터마크를 삽입하기 위해서 해당 $D C T$ 계수를 변경하여도 인간시각이 잘 인식하지 못하는 특성으 로 적용한다. 휘도 분석은 휘도 마스킹 값인, $\alpha_{i, k, k}$ 를 구하 는 과정으로 $\alpha_{i, j, k}$ 는 식 (5)에 의해 구한다. 휘도 마스킹 값 은 영상을 구성하는 $D C T$ 블록들간의 휘도 대비를 고려하 기 위한 것으로 해당 블록의 휘도 값을 조정하여도 인간시 각이 감지할 수 없는 휘도 대비 값을 의미한다.

$$
\alpha_{i, j, k}=\beta_{k} \cdot t[i, j] \cdot\left(\frac{C_{0,0, k}}{\bar{C}_{0,0}}\right)^{T}
$$

여기서 $T$ 는 휘도 마스킹 지수 값으로 [9]에서 0.65를 사 용했다. $\bar{C}_{0.0}$ 는 영상을 구성하는 모든 $D C T$ 블록상의 $D C$ 계수 값들의 평균이다. $C_{0,0, k}$ 는 $k$ 번째 $D C T$ 블록의 $D C$ 값 이다. $\beta_{k}$ 는 (그림 1)의 적응적 워터마킹 모듈을 구성하는 제어기가 워터마크 강도조절을 위해 사용되는 상수이다. $t[i, j]$ 는 환경변화에 대한 인간시각의 기본 반응을 의미하 는 민감도이다. Watson의 $D C T$ 계수 값 민감도 표의 $i, j$ 위치의 값을 의미한다. Watson은 <표 $1>$ 과 같이 $D C T$ 각 계수 값에 대한 인간시각의 기본 민감도를 정의했다[9]. 이 표에서 값이 의미하는 것은 $8 \times 8$ 블록상의 $D C T$ 계수들 각 각에 대하여 임의로 변경하였을 때 인간시각이 감지할 수 없는 변화의 최대 값을 의미한다. <표 1>의 값이 작을수록 그 계수 변환에 대한 인간시각의 기본 민감도가 높다.

〈표 1〉DCT 각 계수 값에 대한 인간시각의 기본 민감도

\begin{tabular}{|l|l|l|l|l|l|l|l|}
\hline 1.40 & 1.01 & 1.16 & 1.66 & 2.40 & 3.43 & 4.79 & 6.56 \\
\hline 1.01 & 1.45 & 1.32 & 1.52 & 2.00 & 2.71 & 3.67 & 4.93 \\
\hline 1.16 & 1.32 & 2.24 & 2.59 & 2.98 & 3.64 & 4.60 & 5.88 \\
\hline 1.66 & 1.52 & 2.59 & 3.77 & 4.55 & 5.30 & 6.28 & 7.60 \\
\hline 2.40 & 2.00 & 2.98 & 4.55 & 6.15 & 7.46 & 8.71 & 10.17 \\
\hline 3.43 & 2.71 & 3.64 & 5.30 & 7.46 & 9.62 & 11.58 & 13.51 \\
\hline 4.79 & 3.67 & 4.60 & 6.28 & 8.71 & 11.58 & 14.50 & 17.29 \\
\hline 6.56 & 4.93 & 5.88 & 7.60 & 10.17 & 13.51 & 17.29 & 21.15 \\
\hline
\end{tabular}

대비 분석은 대비 마스킹을 계산하는 과정이며, 이는 영 상 상의 기존 패턴의 존재 여부에 따라 삽입되는 패턴에 
관한 시각적인 인식정도가 다른 인각시각의 특성이다. 대비 분석을 위해, 한 $D C T$ 블록 내부에서 계수들 간의 휘도조 정 변화를 인식할 수 없는 대비 마스킹 값을 계산하기 위 해 식 (5)에서 계산한 휘도 마스킹 값인 $\alpha_{i, j, k}$ 를 식 (6)에서 활용한다.

$$
W S_{i, j, k}=\operatorname{Max}\left[\alpha_{i, j, k},\left|C_{i, j, k}\right|^{D} \times \alpha_{i, j, k}^{1-p}\right]
$$

여기서, $C_{i, j, k}$ 는 $k$ 번째 블록의 $i, j$ 위치의 계수이고, $p$ 는 스케일 상수로 [9]에서 0.7 을 사-용했다. $W S_{i, j, k}$ 는 대비 마 스킹 값인 동시에 $k$ 블록상의 $i, j$ 위치에 할당 가능한 최 대 워터마크의 강도를 의미한다.

\section{5. 적응적 워터마크 삽입과 추출}

적응적 워터마킹 단계에서는 워터마크 검출의 정확도와 강 인성을 높이기 위해 시각적 무감지성 조건을 만족하는 최대 의 워터마크 강도를 산출한다. 이 강도는 다음에 소개하는 단 계 1 에서 단계 5 까지를 반복 수행하여 산출된다. 이 과정의 의미는 시각적 무감지성을 만족하는 최대의 $\beta_{k}$ 값을 찾는 과 정이다.

\section{[step 1] 영상을 재배열한다.}

영상을 재배열하는 이유는 연산의 호율성을 위함이다. 영 상 재배열 과정은 $8 \times 8 \mathrm{DCT}$ 블록의 $\mathrm{DC}$ 영역과 중간 주파 수 영역 사이에 있는 $D C T$ 계수들 중 일부를 취하여 순서 대로 (그림 2)와 같이 $4 \times 4$ 블록을 만드는 과정이다. 단, (그림 2)에 있는 숫자는 지그재그 스캔 순서이다. 단계 1에 서는 워터마킹 정보수집기의 텍스쳐 분석 과정의 분류결과 를 사용한다. 분류된 블록가운뎨 단순한 블록 $C_{1}$ 을 제외한 $C_{2}$ 와 $C_{3}$ 가 워터마크 삽입대상 블록이며 각 경우의 삽입 위치는 (그림 2)와 같다.

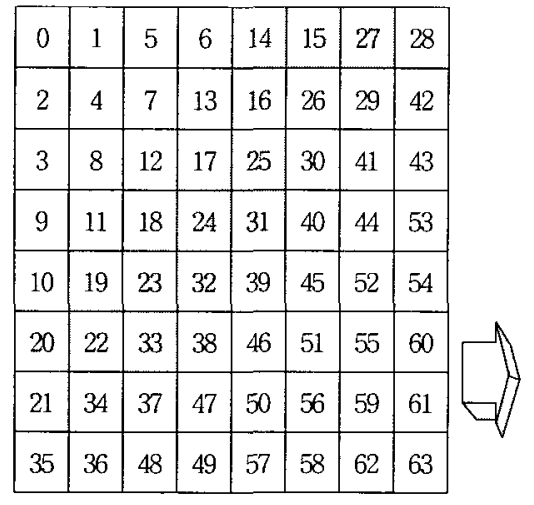

(a) $\mathrm{C}_{2}$ 의 경우

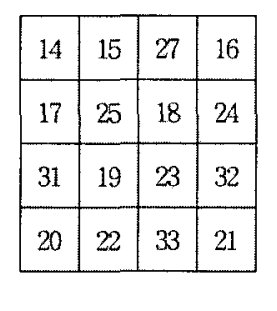

[step 2] 극성(polarity)을 계산한다.

극성은 복잡도가 보통인 불록 $C_{2}$ 와 복잡한 블록 $C_{3}$ 의 각 경우를 구분하여 계산하며, 먼저 식 (7)을 만족하는 블록의 쌍을 구한다. 즉, $\mathrm{n}$ 개의 재배열된 블록들의 두 부분집합을 $R_{a}=\left\{a_{1}, a_{2}, \cdots, a_{n / 2}\right\}, R_{b}=\left\{b_{1}, b_{2}, \cdots, b_{n / 2}\right\}$ 라 할 때, 두 부분집합예 속하는 블록간의 쌍을 이루는 방법은 식 (7)의 사상함수 $\boldsymbol{M}$ 에 기초한다. 사상함수 $\boldsymbol{M}$ 에서 블록간의 사상 은 보안키를 사용해서 생성한 의사랜덤 숫자에 의해 결정 된다.

$$
R_{a}=M\left(R_{b}\right) \text { 단, } R_{a} \cap R_{b}=\varnothing, R_{a} \cup R_{b}=\cup
$$

식 (7)을 만족하며 쌍으로 선택된 두 개의 $4 \times 4$ 블록을 각각 $A, B$ 라고 할 때, 두 개의 블록으로부터 만들어지는 4 $\times 4$ 크기의 극성은 식 (8)에서 보는 것과 같이 블록 $A, B$ 간의 정합되는 계수의 차로부터 계산된다.

$$
\begin{aligned}
& \text { if } A_{i, j} \geq B_{i, j} \text { then } P_{i, j, k}=1 ; \\
& \text { else } P_{i, j, k}=0 ; \text { (단, } 0 \leq i, j<4,0<k \leq n / 2 \text { ) }
\end{aligned}
$$

워터마크 삽입시 극성을 이용하는 것은 다음과 같은 세 가지 이유 때문이다. 첫째, 워터마크의 시각적 무감지성 향 상 둘째, 다양한 압축률의 JPEG 연산 후에도 강건하게 워 터마크 정보 유지 셋째, 워터마크의 보안성 강화이다.

[step 3] 워터마크 삽입 기준 정보를 계산한다.

이 단계의 목적은 워터마크를 삽입하기 위한 기존 $D C T$ 계수의 변형 기준을 얻는 것이다. 삽입할 워터마크 영상을 극성 크기와 같은 $4 \times 4$ 블록으로 분할하고 이를 $W_{k}$ 라 하 면, 워터마크 삽입 기준 정보인 $\hat{p}_{k}$ 는 식 (9)과 같이 $W_{k}$ 와 극성 $P_{k}$ 간의 배타적 $\mathrm{OR}(\oplus$ ) 연산에 의해 구해진다. (그림 $3)$ 은 식 (9)의 과정을 보여준다.
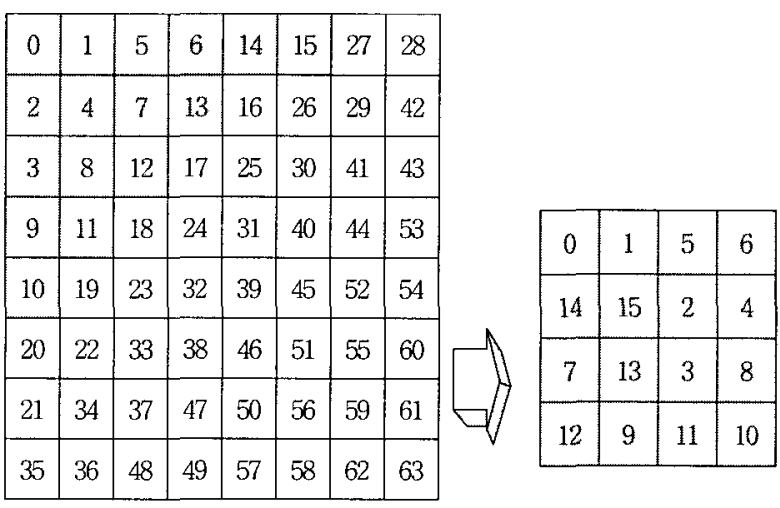

(b) $\mathrm{C}_{3}$ 의 경우 
$\widehat{P}_{k}=P_{k} \oplus W_{k}$

$\widehat{P}_{k}=\left\{\widehat{P}_{i, j, k} \quad 0 \leq i, j<4\right.$ and $\left.0<k \leq n / 2\right\}$

\begin{tabular}{|l|l|l|l|}
\hline 1 & 0 & 1 & 1 \\
\hline 1 & 0 & 1 & 0 \\
\hline 0 & 1 & 1 & 0 \\
\hline 1 & 0 & 0 & 1 \\
\hline
\end{tabular}

$P_{k}$

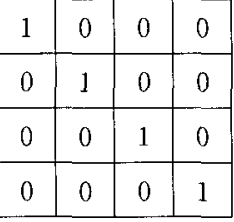

$\oplus$
$\mathrm{W}_{\mathrm{k}}$

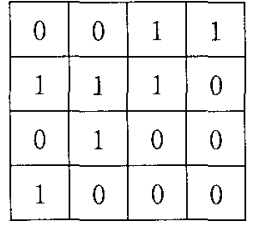

$\widehat{P}_{k}$
(그림 3) 워터마크 삽입 기준 정보계산

[step 4] 워터마크를 삽입한다.

워터마크 추출시 워터마크가 반영된 워터마크 삽입 기준 정보인 $\widehat{P}_{k}$ 가 정확히 구해지도록 기존의 $D C T$ 계수를 조정 한다. 워터마크 삽입은 식 (7)에 의해 선택된 두 개의 블록 을 $A_{k}$ 와 $B_{k}$ 라 하면, 두 개의 블록 중에서 부분집합 $R_{b}$ 에 속하는 블록 $B_{k}$ 을 선택한 후, 단계 3 에서 구해진 $\widehat{P}_{k}$ 를 이

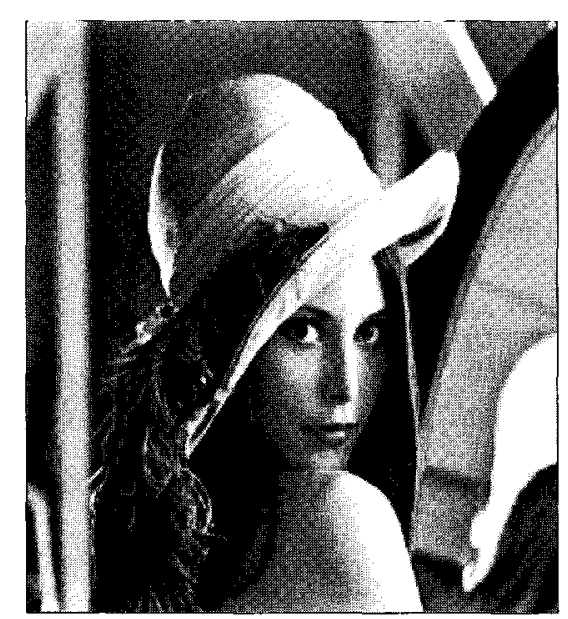

(a) 입력영상

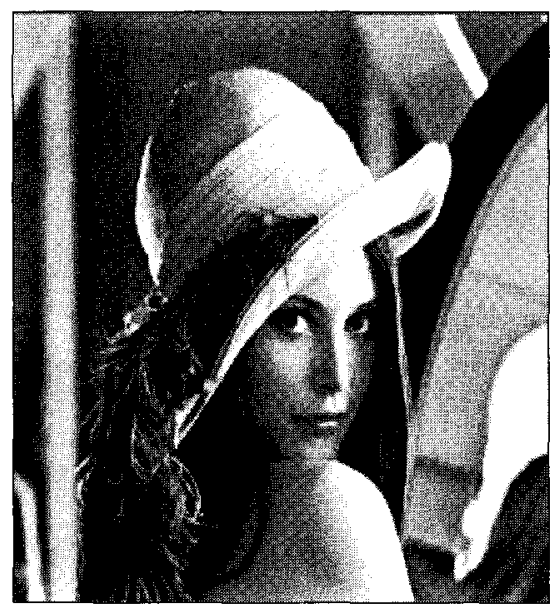

(d) 워터마크가 삽입된 영상

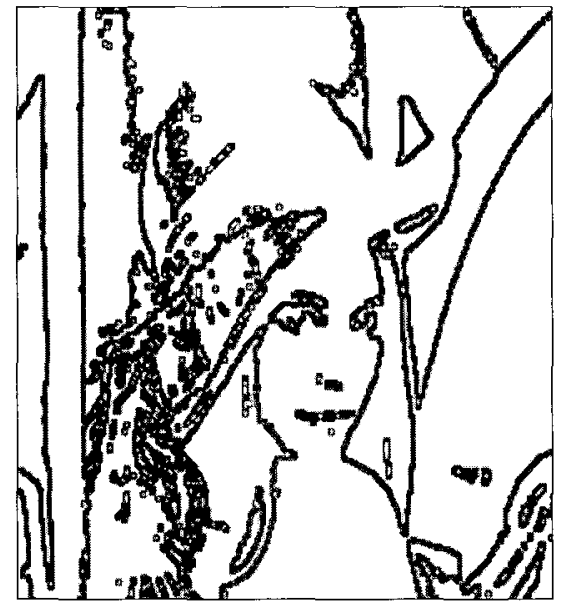

(b) 식 (2)에 의해 검출된 에지중 제외될 대상 에지
용하여 $B_{k}$ 의 $D C T$ 계수를 조정함으로 이루어진다. 계수 조 정 후의 $B_{k}$ 블록을 $\bar{B}_{k}$ 라 하면, $D C T$ 계수를 조정하는 방 법은 식 (10)과 같다. 즉, $\widehat{P}_{k}$ 의 값이 1 이면 $\left(\bar{B}_{k}-B_{k}\right) \geq W$ $S_{i, j, k}$ 가 되도록, $\widehat{P}_{k}$ 의 값이 0 이면 $\left(\bar{B}_{k}-B_{k}\right)<W S_{i, j, k}$ 가 되도록 계수값을 변경한다.

$$
\bar{B}_{k}=B_{k}+\left(2 \widehat{P}_{k}-1\right) \times W S_{i, j, k}
$$

워터마크된 픽셀값 $\bar{B}_{k}$ 와 입력 $D C T$ 계수 $B_{k}$ 간의 차에 대한 절대 값의 크기 $\left|\bar{B}_{k}-B_{k}\right|$ 는 식 (10)에서 워터마크 강 도 $W S_{i, j, k}$ 이며, 이 값이 클수록 워터마크 추출기에서 워터 마크를 추출하는 정확도는 향상 된다.

[step 5] 영상을 역으로 재배열한다.

단계 5 는 단계 1 의 역과정으로써 워터마크가 삽입된 $4 \times$ 4 블록상의 각 계수 값을 $8 \times 8$ 계수 블록의 해당 좌표 상 의 기존 계수 값으로 갱신하는 과정이다. 
단계 5 이후 최종적으로 $I D C T$ 를 수행하여 워터마크가 삽입된 영상을 생성한다. 이 때, 입력영상을 $C^{0}$, 워터마크 가 삽입된 영상을 $C^{W}$ 라 하면, 이 두 영상간의 시각적 지 각거리는 식 $(11)$ 을 사용하여 계산한다.

$$
\begin{aligned}
& D_{C^{w}-C^{o}}=\left(\sum_{i, j, k}\left|d_{i, j, k}\right|^{p}\right)^{\frac{1}{p}} \\
& d_{i, j, k}=\frac{e_{i, j, k}}{W S_{i, j, k}} \\
& e_{i, j, k}=C_{i, j, k}^{W}-C_{i, j, k}^{o}
\end{aligned}
$$

워터마크 삽입 후 시각적 지각거리를 산출하고, 그 값 이 식 (14)와 같이 목표하는 워터마크의 시각적 무감지 값

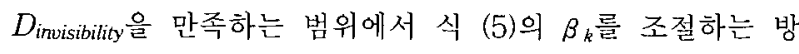
법으로 워터마크의 강도를 조절한다. $\beta_{k}$ 의 조절은 실험에 의 존한다.

$$
\beta_{k}=\frac{D_{\text {invisibitty }}}{D_{C^{w}-C^{0}}}
$$

워터마크 추출 과정은 워터마크 삽입과정과 윳사하다. 워 터마크 추출시 워터마크 삽입위치, 사상함수 $M, P_{k}$ 와 $\widehat{P}_{k}$ 를 알고 있으므로 식 (15)에 의해 $W_{k}$ 를 구할 수 있다.

$$
W_{k}=P_{k} \oplus \widehat{P}_{k}
$$

$$
W_{k}=\left\{W_{i, j, k} 0 \leq i, j<4 \text { and } 0<k \leq n / 2\right\}
$$

\section{6. 실험 결과}

제안하는 방법에 대한 실험 환경은 인텔 Pentium $4 \mathrm{CPU}$ $1.7 \mathrm{GHz}, \mathrm{RAM} 256$ 의 시스템과 윈도우 XP 운영체제를 사용 하였고 Visual $\mathrm{C}++6.0$ 으로 프로그램을 작성하였다. 제안한 방법을 검증하기 위하여 $512 \times 512$ 크기의 $L E N A$ 와 $B A R B A$ $R A$ 영상에 적용하여 실험하였고, 제안한 방법과 기존의 방 법[10]과 비교하여 성능을 평가하였다. 먼저 워터마크의 시 각적 무감지성과 워터마크의 검출율을 평가하고 다음으로 절단, 영상강화, 저주파 필터링, $\mathrm{JPEG}$ 압축의 영상처리 공 격에 대한 제안된 방법의 강인성을 평가한다.

워터마크의 시각적 무감지성은 (그림 5)(b)와 (그림 5)(c) 를 비교함으로 평가할 수 있다. 제안한 방법은 텍스쳐 분석 을 통해 워터마크 삽입시 워터마크를 삽입하여도 셥게 인식 할 수 없는 영역에 워터마크를 삽입한다. 특히, 워터마크 삽 입시 노출 가능성이 높은 물체의 경계를 제외한 복잡한 텍스 쳐 영역에 워터마크를 삽입함으로 삽입한 워터마크의 노출을 막아 워터마크의 시각적 무감지성을 항상시킨다. (그림 5)(c) 에서 대부분의 워터마크는 물체의 경계영역이 제외된 모자의 깃털, 모발과 같은 복잡한 텍스쳐 영역에 집중 분포한다.

(그림 5)(a) 영상의 오른쪽 눈 영역에 해당하는 두 블록

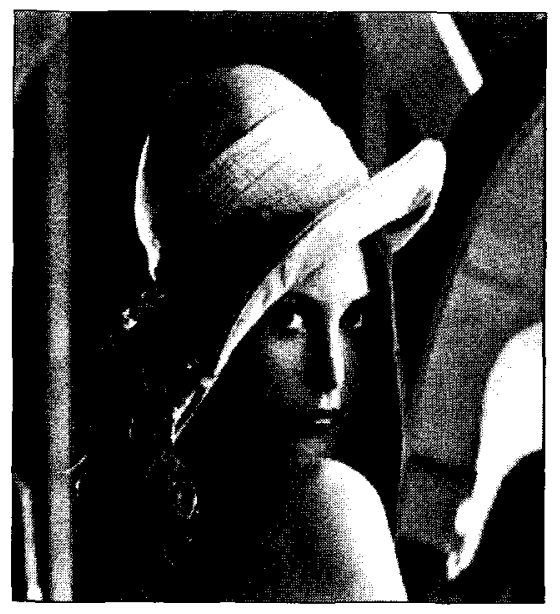

(a) 입력영상

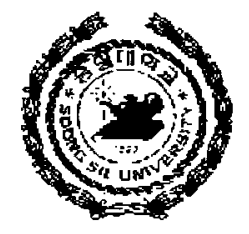

(d) 워터마크

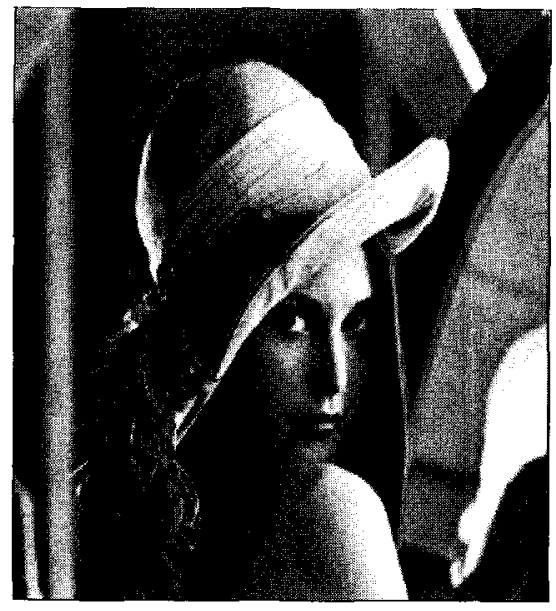

(b) [10]의 방법으로 워터마크가 삽입된 영상

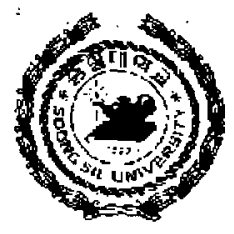

(e) b에서 추출한 워터마크

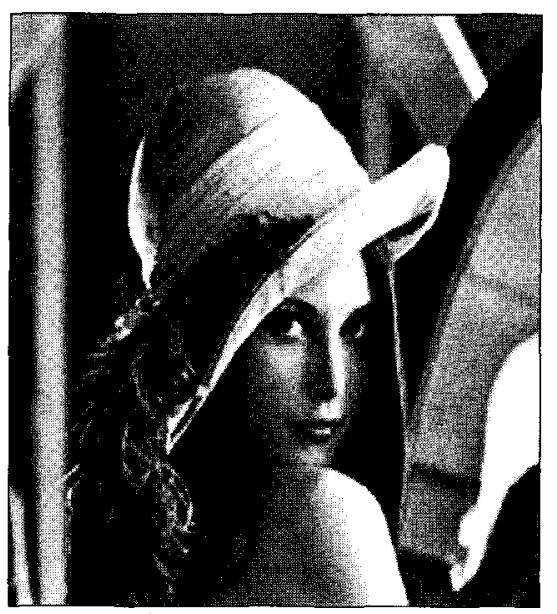

(c) 제안하는 방법으로 워터마크가 삽압된 영상

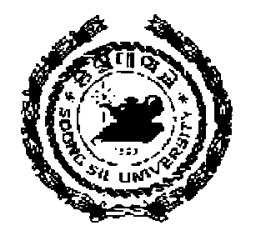

(f) c에서 추출한 워터마크

(그림 5) 워터마크의 시각적 무감지성 비표 
을 고려할 때, 두 블록은 식 (2), 식 (3), 식 (4)와 알고리즘 1 에 의한 텍스쳐 분석 결과 충분히 복잡한 블록 $\mathrm{C}_{3}$ 로 분류 된다. 그러므로, 워터마크 삽입 대상이 되며, 삽입 후보 위 치는 (그립 6)에서 음영부분이다.

\begin{tabular}{|c|c|c|c|c|c|c|c|}
\hline 72 & -18 & -3 & -20 & -16 & -4 & -6 & -1 \\
\hline 51 & $-\pi$ & 2 & 45 & 11 & 1 & 2 & 3 \\
\hline 31 & -2 & -7 & -8 & 5 & 5 & 10 & 7 \\
\hline 73 & 4 & -21 & -7 & 1 & -13 & -2 & -2 \\
\hline 19 & 12 & -21 & -17 & 4 & 2 & 2 & -1 \\
\hline 20 & 15 & -2 & -17 & -5 & 2 & 0 & -1 \\
\hline 16 & 16 & 13 & 1 & 2 & 6 & -2 & 0 \\
\hline-1 & -3 & -6 & -12 & -6 & -1 & 1 & 3 \\
\hline
\end{tabular}

(a)

\begin{tabular}{|c|c|c|c|c|c|c|c|}
\hline 486 & 91 & -66 & -91 & -17 & -1 & 14 & 0 \\
\hline 140 & 41 & 44 & 35 & -8 & -12 & -6 & -4 \\
\hline 43 & 108 & -54 & 5 & 16 & 13 & -9 & 0 \\
\hline-143 & -21 & 84 & 34 & 2 & 0 & -12 & 6 \\
\hline 9 & -18 & -2 & -32 & 8 & 5 & 5 & 12 \\
\hline-23 & -9 & 1 & -1 & -8 & 1 & 2 & 0 \\
\hline 3 & 10 & -14 & 4 & 6 & -1 & -1 & -6 \\
\hline-8 & -10 & 14 & 3 & -1 & -2 & -2 & -3 \\
\hline
\end{tabular}

(b)
(그림 6) (그림 5)(a) 영상의 오른쪽 눈 영역에 해당하는 두 개의 DCT 블록

워터마크 강도 산출은 시각 마스킹 값을 구하는 것으로 휘도 마스킹 값과 대비 마스킹 값을 구하는 것이다. (그림 6)(b) 블록의 첫 번째 계수에 대해 휘도 마스킹 값을 구하기 위해 식 (5)에 $\beta_{k}$ 를 1 로, 인간시각의 기본 민감도 값 $\mathrm{t}[0,0]$ 를 <표 1>의 $(0,0)$ 위치의 값 1.40 으로, 휘도 마스킹 지수 값 $T$ 를 0.65로, (그림 5)(a) 영상을 구성하는 모든 $D C T$ 블 록상의 $D C$ 계수 값의 평균 $\bar{C}_{0.0}$ 을 768.8 , (그림 6 )(b)블록 의 $D C$ 값에 해당하는 $C_{0,0}$ 에 486 을 대입하면 휘도 마스킹
값은 1.03 이다. 구한 휘도 마스킹 값인 1.03 을 식 (6)에 적 용하여 대비 마스킹 값을 계산하면 76.8 이다. 이는 두 번째 블록 상의 $(0,0)$ 위치에 할당 가능한 최대 워터마크 강도 값 $\left(W S_{0,0}\right)$ 이다. 이런 방식으로 (그림 6$)(\mathrm{b})$ 의 모든 계수에 대해 휘도 마스킹 값과 대비 마스킹 값을 구하면 (그림 7) 과 같다. 워터마크 삽입 후 시각적 무감지성 검사 결과 식 (5)의 $\beta_{k}$ 값은 1.3 이 적용 되었다.

\begin{tabular}{|c|c|c|c|c|c|c|c|c|c|c|c|c|c|c|c|}
\hline & 0.25 & -0.23 & $-0.41\}$ & -0.20 & -0.04 & \begin{tabular}{|l|}
0.35 \\
\end{tabular} & 0 & \begin{tabular}{|l|}
76,8 \\
\end{tabular} & $\begin{array}{ll}1-5,5 \\
\end{array}$ & 12.16 & 18.05 & 4.49 & 0.39 & 4.64 & 0 \\
\hline 8 & 0.21 & 0.39 & 0.20 & $|-0.10|$ & $|-0.18|$ & $|-0.15|$ & $\mid-0.16$ & 2287 & 8.49 & 8.79 & 7.47 & 2.16 & 3.42 & 200 & 1.52 \\
\hline & 0.36 & -0.39 & 0.09 & 0.24 & 0.25 & \begin{tabular}{|l|}
-0.25 \\
\end{tabular} & & 839 & 19.64 & 1238 & 1.53 & 4.54 & 400 & 3.09 & 0 \\
\hline-0.12 & $|-0.14|$ & 0.61 & $0 \mid 0.49$ & 0.45 & 0 & -0.42 & 0.32 & 3.38 & 4,73 & 19.20 & 9.56 & 6.85 & 0 & 4.39 & 250 \\
\hline 0.13 & -0.17 & -0.06 & \begin{tabular}{|l|}
-0.57 \\
\end{tabular} & \begin{tabular}{|l|}
0.31 \\
\end{tabular} & 0.28 & 0.33 & 0.68 & \begin{tabular}{|l|}
254 \\
\end{tabular} & 4.47 & 0.70 & 9.58 & 3.03 & 2.11 & 2.21 & 5.07 \\
\hline-0.35 & $|-0.15|$ & 0.04 & $-0.07 \mid$ & $|-0.38|$ & \begin{tabular}{|l|l|} 
\\
\end{tabular} & \begin{tabular}{|l|l|} 
\\
\end{tabular} & & 6.55 & 2.63 & 0.40 & 0.45 & 3.21 & 0.53 & 1.06 & 0 \\
\hline 0.13 & $\mid 0.21$ & -0.34 & \begin{tabular}{|l|}
0.20 \\
\end{tabular} & 0.37 & $\mid-0.15$ & $-0.19 \mid$ & $\mid-0.73$ & 1.17 & 3.17 & 4.59 & 1.64 & 2.60 & 0.57 & 0.61 & 3.19 \\
\hline-0.33 & $-0.29 \mid$ & \begin{tabular}{|l|l} 
\\
\end{tabular} & \begin{tabular}{|l|}
0.20 \\
\end{tabular} & -0.13 & $|-0,28|$ & -0.36 & $\mid-0.57$ & 3.09 & 3.46 & 4.94 & 1.34 & 0.54 & 1.11 & 1.19 & 18 \\
\hline
\end{tabular}
(a) 휘도 마스킹 값
(b) 대비 마스킹 값

(그림 7) (그림 6)(b)의 휘도와 대비 마스킹 값

워터마크의 검출율 실험을 위하여 기존의 방법 [10]과 제 안한 방법으로 (그림 5)와 (그림 8)(d) 영상을 실험영상 (그 림 5)와 (그림 8)(a)에 삽입하고 로고영상을 검출하였다. <포 $2>$ 는 그 검출결과를 비교하여 나타내었다. <표 2>에서 보 듯이 졔안한 방법이 기존방법 [10]보다 더 높은 검출율을 보 여주었다. 따라서, 검출율에 있어서 제안한 방법이 기존의

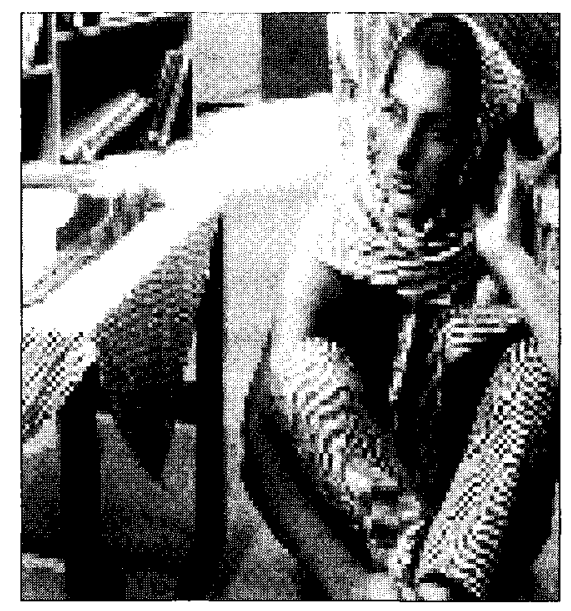

(a) 입력영상

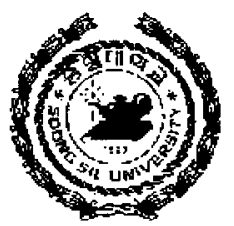

(d) 워터마크

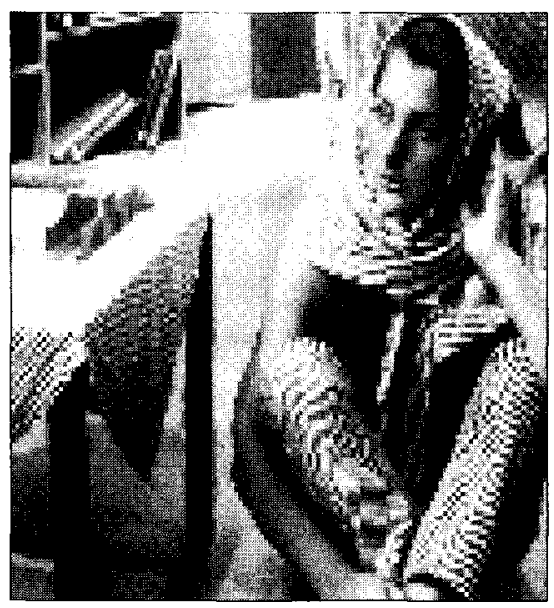

(b) [10]의 방법으로 워터마크가 삽입된 영상

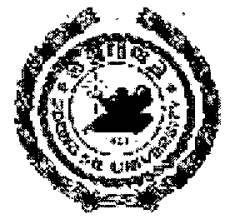

(e) b 에서 추출한 워터마크

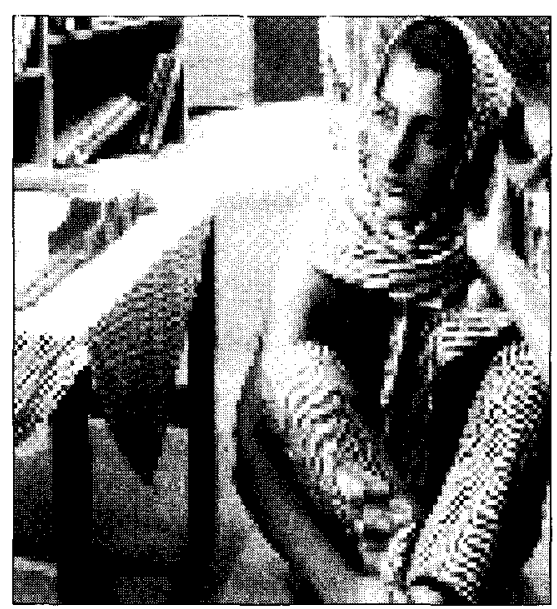

(c) 제안하는 방법으로 워터마크가 삽입된 영상

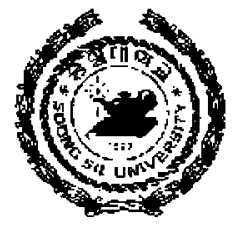

(f) c 에서 추출한 워터마크

(그림 8) 워터마크의 시각적 무감지성 비교 
〈표 2〉워터마크 검출율(\%)

\begin{tabular}{|l|c|c|c|c|c|}
\hline \multirow{2}{*}{ 영 상 } & 방빕[10] & • 텍스쳐 분석 & • 휘도와 대비 분석 & $\begin{array}{l}\text { - 텍스쳐 분석 } \\
\text { - 휘도와 대비 분석 }\end{array}$ & $\begin{array}{l}\text { - 텍스쳐 분석 } \\
\text { - 휘도와 대비 분석 } \\
\text { - 워터마크 강도 제어기 }\end{array}$ \\
\hline LENA & 95.79 & 96.98 & 95.79 & 98.35 & 99.79 \\
\hline BARBARA & 92.79 & 97.98 & 95.90 & 98.15 & 99.20 \\
\hline
\end{tabular}

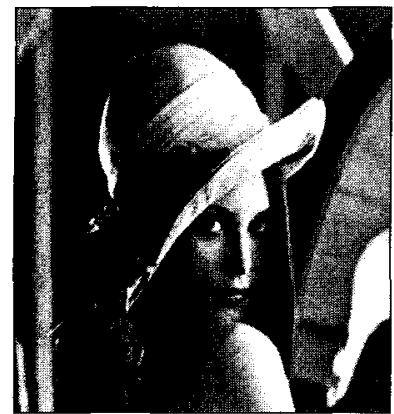

(a) 입력영상

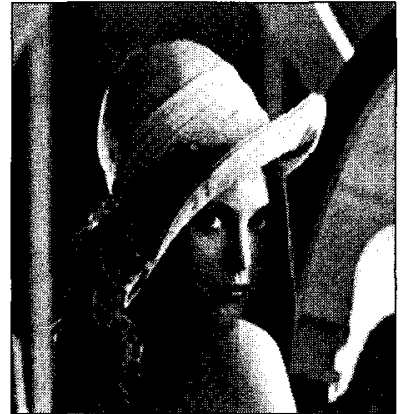

(b) 워터마크가 삽입된 영상
VISION

$L A B$

(c) 워터마크

\section{VISION}

$L A B$

(그림 9) 워터마크의 강인성 비교 기준

방법 [10]보다 개선되었음을 알 수 있다. 검출율 측정 방법 은 식 (16)과 같다.

워터마크 검출율 $(\%) \frac{\text { 정확히 추출된 워터마크비트 }}{\text { 전체 삽입한 워터마크비트 }} \times 100$

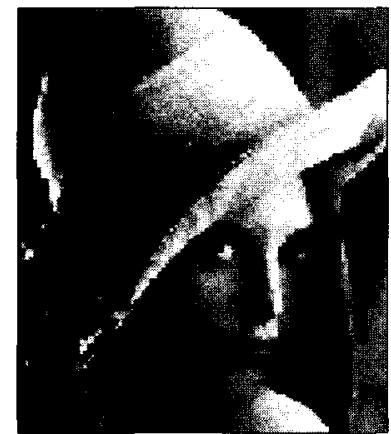

(a) 영상 b를 절단 후, 압축률 7.16 의 JPEG 압축

(그람 10)

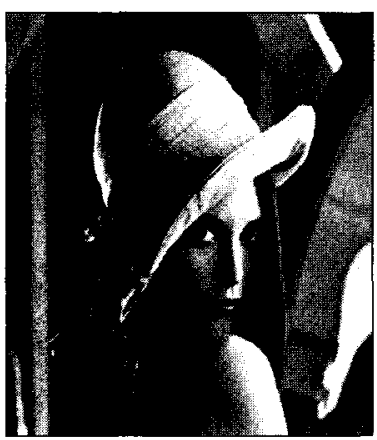

(a) 영상 b에 대비값 5 증가 (b) 워터마크 검출율 $(96 \%)$

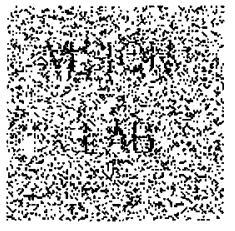

(b) 워터마크 검출율(90\%)

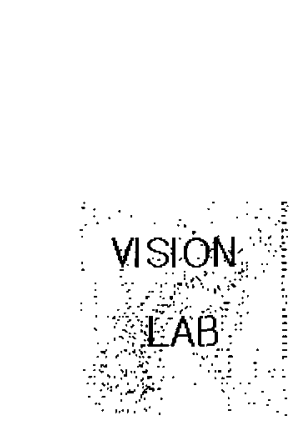

그림 11)
제안한 방법의 다양한 영상처리 공격에 대한 강인성에 대한 실험 결과를 (그림 9)를 기준으로 (그림 10)에서 (그 림 14)까지 보이고 방법 [10]과 제안한 방법간의 성능 비교 를 <표 3>에서 보인다.

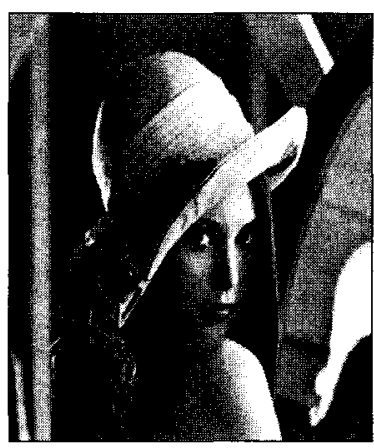

(a) 영상 b에 대비값 20 증가

(b) 워터마크 검출율(96\%)
(그림 12)

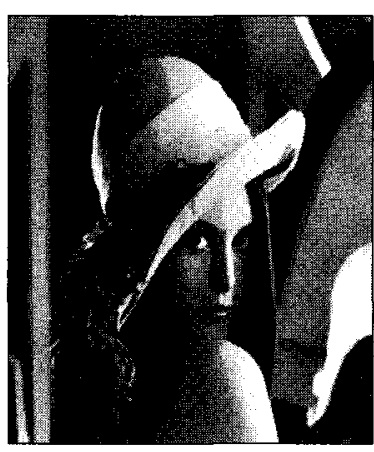

(a) 영상 $\mathrm{b}$ 에 저주파 필터랑 (b) 워터마크 검출울(93\%)
VISION

LAB
(그림 13) 


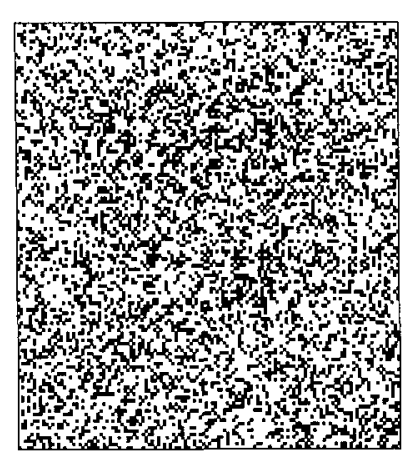

(a) 압축율 9.1 , 검출율 $65 \%$

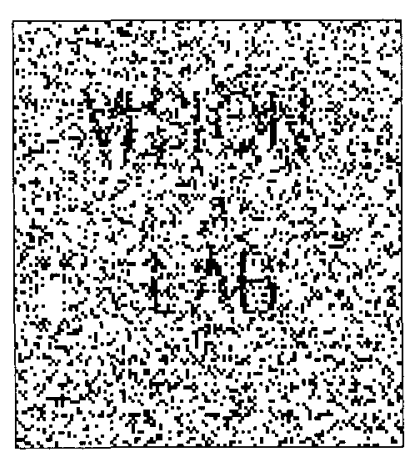

(b) 압축율 8.4 , 검출율 $70 \%$

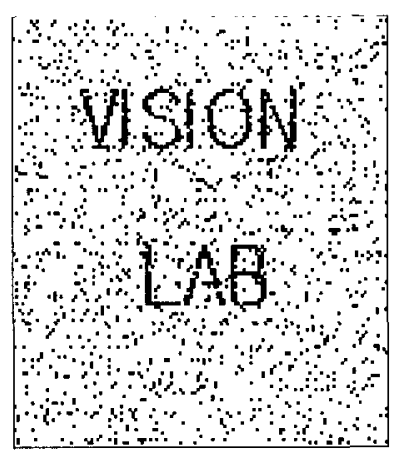

(c) 압축율 7.1, 검출율 $91 \%$

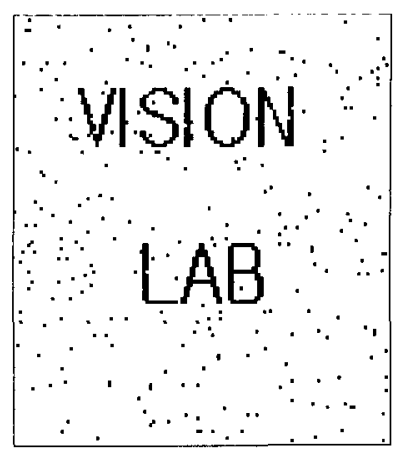

(d) 압축율 5.9 , 검출율 $99 \%$

(그림 14) 영상 b에 JPEG 압축

〈표 3〉 방법[10]과 제안한 방법간의 성능 비교

\begin{tabular}{|c|c|c|c|}
\hline \multirow{2}{*}{\multicolumn{2}{|c|}{ 공격유형 }} & \multicolumn{2}{|c|}{ 워터마크 검출율(\%) } \\
\hline & & 방 법[10] & 제안된 방법 \\
\hline \multicolumn{2}{|c|}{ 절단 공격후, JPEG공격(압축율 7.16) } & 89.6 & 90.1 \\
\hline \multirow{2}{*}{ 영상 강화 } & 대비값 5증가 & 96.5 & 96.5 \\
\hline & 대비값 10 증가 & 96.3 & 96.3 \\
\hline \multicolumn{2}{|c|}{ 저주파 필터링 } & 91.5 & 93.2 \\
\hline \multirow{4}{*}{ JPEG 압축 } & 압축율 9.1 & 64.9 & 65.6 \\
\hline & " 8.4 & 68.2 & 70.3 \\
\hline & $\begin{array}{ll}1 & 7.1 \\
\end{array}$ & 90.6 & 91.1 \\
\hline & " 5.9 & 98.9 & 99.3 \\
\hline
\end{tabular}

\section{7. 결론 및 향후 연구}

본 논문에서는 워터마크가 삽입되는 블록의 선택과 블록에 삽입하는 워터마크 강도의 결정을 워터마크를 삽입할 대상 블록에 대한 인간의 시각적인 특성을 반영하여 적응적으로 조절함으로 워터마크의 시각적 무감지성과 워터마크 검출율 을 높였다. 특히, 본 논문에서는 $\mathrm{DCT}$ 블록의 $\mathrm{DC}$ 계수를 활 용하여 워터마크 삽입 강도를 결정하고 저주파 영역에 워터 마크를 삽입함으로 절단, 영상강화, 저주파 필터링, JPEG 압 축의 다양한 워터마크를 제거하고자 하는 영상처리 공격에 대해 강인했다. 만일 워터마크 삽입 대상 영상이 칼라인 경 우, 제안된 방법의 적용 대상 채널은 시각에 민감하지 않은 블루채널이다. 향후연구는 회전, 이동, 크기변환 둥의 기하 학적 공격에 강인한 워터마킹과 제안된 방법을 동영상에 적 용하는 것으로 고려된다.

\section{참 고 논 문}

[1] F. Hartung and M. Kutter, "Multimedia Watermarking Technique," Proc. IEEE, Vol.87, pp.1079-1107, 1999.

[2] E. Koch and J. Rindfrey and J. Zhao, "Copyright Protection for Multimedia Data," In Digital Media and Electronic Publishing. Academic Press, London, pp.203-213, 1996.

[3] A. Bors and I. Pitas, "Image Watermarking Using DCT Domain Constraints," in Proc. IEEE Int. Conf. on Image Proce- ssing, Lausanne, Switzerland, pp.231-234, September, 1996.

[4] G. Langelaar, R. Lagendijk, and J. Biemond, "Watermarking by DCT Coefficient Removal : Statistical Approach to Optimal Parameter Settings," in SPIE Photonics West, San Jose, CA, http://www-it.et.tudelft.nl/ $/$ gerhard/spie99.zip, January, 1999.

[5] M. D. Swanson, M. Kobayashi and A. H. Tewfik, "Multi-. media Data Embedding and Watermarking Technologies," in Proc. IEEE., Vol.86(6), pp.1064-1087, 1998.

[6] C. Podilchuk and W. Zeng, "Perceptual Watermarking of Still Images," in Proc. of Workshop Multimedia Signal Pro-

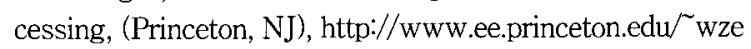
ng/wm_workshop.html, June, 1997.

[7] S. Craver, et al., "Resolving rightful ownership with invisible watermarks techniques : limitations, attacks, and implications," IEEE Journal of Selected Areas in Communications, Vol.16, No.4, pp.573-586, 1998.

[8] HUERTAS, A., MEDIONI, G., "Detection of Intensity Changes with Sbupixel Accuracy Using Laplacian-Gaussian Masks," IEEE Trans. Pattern Anal. Mach. Intell, PAMI-8 (5), pp.651-664, 1979.

[9] A. B. Watson, "DCT Quantization Matrices Visually Optimized for Individual Images," in Proc. SPIE, Bellingham, WA, pp.202-216, 1993.

[10] M. Kutter, F. Jordan and F. Bossen, "Digital signature of color images using amplitude modulation," Proc. of SPIE EI97, pp.518-526, Feb., 1997.

[11] M. D. Swanson, M. Kobayashi and A. H. Tewfik, "Multimedia Data Embedding and Watermarking Technologies," Proc. IEEE, Vol.86, pp.1064-1087; 1998.

[12] R. B. Wolfgang, C. I. Podilchuk and E. J. Delp, "Perceptual Watermarking for Digital Image and Video," Proc. IEEE, Vol.87, pp.1108-1126, 1999.

[13] I. J. Cox, "Watermarking of Image Data Using MPEG/JPEG Coefficients," United States Patent, http://www.neci.nec.com/ patents/patents.html, 2000.

[14] I. J. Cox, M. L. Miller and A. MeKellips, "Watermarking as Communications with Side Information," Proc. IEEE, Vol. 87, pp.1127-1141, 1999.

[15] E.-C. Chang and M. Orchard, "Geometric Properties of Watermarking Schemes," IEEE International Conference on Image Processing, pp.1609-1612, 2000. 


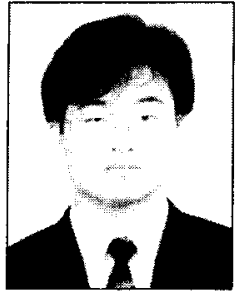

전 영 민

e-mail : ymjun@vision.ssu.ac.kr

1997년 군산대학교 컴퓨터과학과(이학사)

1999년 숭실대학교 대학원 컴퓨터학과

(공학석사)

1999년 현재 숭실대학교 대학원 컴퓨터 학과 박사수료

관심분야: 컴퓨터 비전, 패턴인식, 디지털 워터마킹, 인터패이스 에이전트 등

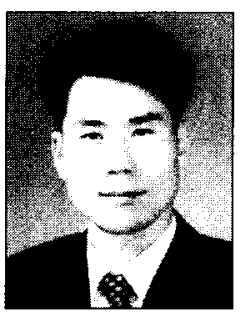

\section{김 계 영}

e-mail : gykim@computing.ssu.ac.kr 1990년 숭실대학교 전자계산학과(공학사)

1992년 숭실대학교대학원 컴퓨터학과 (공학석사)

1996년 숭실대학교대학원 컴퓨터학과 (공학박사)

1996년 1997년 한국전자통신연구원(Post Doc.)

1997년 2001년 한국전력공사 전력연구원 선임연구원

2001년 현재 숭실대학교 컴퓨터학부 조교수

관심분야 : 컴퓨터비전, 형태인식, 생체인식, 증강현실, 영상 및 신호처리 등

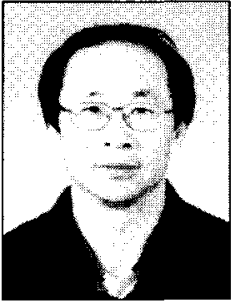

\section{최 형 일}

e-mail : hic@computing.ssu.ac.kr

1979년 연세대학교 전자공학과(공학사)

1982년 미시간대학교 전산공학과(공학

석사)

1987년 미시간대학교 전산공학과(공학 박사)

1987년 현재 숭실대학교 미디어학부 교수

관심분야 : 컴퓨터비전, 패턴인식, 퍼지이론, 비디오 검색, 인터 페이스 에이전트 등 